\title{
İstanbul Şile'de Sürücü ve Yolcuların Emniyet Kemeri Kullanımı: Gözlem Çalışması
}

\author{
Emrah Duran', Ŏguzhan Ordu', Burcu Tekeş ${ }^{2 *}$ \\ ${ }^{1}$ Psikoloji Bölümü, FVM Işı1k Üniversitesi, İstanbul Türkiye. \\ ${ }^{2}$ Güvenlik Araştırma Birimi, Psikoloji Bölümü, Orta Doğu Teknik Üniversitesi, Ankara Türkiye.
}

$\ddot{O} \mathbf{z}$

Emniyet kemeri kullanımının trafik kazalarında hayat kurtardığı ve yaralanma riskini önemli derecede azalttığı kanıtlanmasına rağmen Türkiye'de emniyet kemeri kullanım oranları halen yeterli düzeyde bulunmamaktadır. Bu çalışmanın temel amacı, İstanbul ilinin Şile ilçesindeki emniyet kemeri kullanımının araçtaki pozisyona, cinsiyete ve farklı gözlem bölgelerine göre değişip değişmediğinin gözlemlenmesidir. Bu gözlem çalışması farklı bölgelerdeki (Kampüs-içi, Kampüs girişi, Şile Otobanı, Şile Kırsalı) sürücülerden eşit bir örneklem oluşturularak $(N=400)$ gerçekleştirilmiştir. Emniyet kemeri kullanımına etki eden faktörleri (araçtaki pozisyon, cinsiyet ve bölgeler) analiz etmek amacıyla Ki-Kare Bağımsızlık Testi uygulanmıştır. Verilerin analizi sonucunda emniyet kemeri kullanımı dağılımlarının gözlem bölgeleri, araçtaki pozisyon, cinsiyet ve araç tiplerine göre anlamlı bir şekilde farklılaştı̆̆ görülmüştür. Buna göre emniyet kemeri kullanımının; bölgelere göre otobanda, araç içi pozisyona göre ise sürücülerde, cinsiyete göre kadınlarda ve araç tiplerine göre otomobil sürücülerinde diğerlerinden daha yüksek olduğu gözlemlenmiştir. Emniyet kemeri kullanımının pratik sonuçları, araştırmanın güçlü yönleri, katkıları ve sınırlılıkları ilgili alanyazın ışı̆̆ında tartışılmıştır.

Anahtar kelimeler: emniyet kemeri, gözlem, cinsiyet, kentsel yol, kırsal yol

\section{The Seat Belt Use of Drivers and Car Occupants: An Observation Study in Şile, Istanbul}

\begin{abstract}
Although the effectiveness of the seat belt use is widely documented in reducing injury risk and saving lives, the rate of seat belt usage in Turkey is not yet at a sufficient level. The main purpose of present study is to observe whether the use of the seat belt in Şile district of Istanbul varies according to the position in the vehicle, gender, and different regions. The study was carried out with equal numbers of observations of vehicles $(N=400)$ from different regions (inside the campus, campus entrance, Şile urban road (highway), Şile rural road). In order to analyze the factors which, affect seat belt use, (i.e. position in the vehicle, gender, and different regions) chi-square analyses were conducted. The results showed that the use of seat belt significantly differed according to the position in the vehicle, gender, and different regions. Accordingly, seat belt use is significantly higher in urban roads (as compared to rural roads), drivers (as compared to passengers), females (as compared to males), and automobile drivers (as compared to passengers and other vehicle types). The practical implications of seat belt use, the strengths and limitations of the present study were discussed in the light of the literature.
\end{abstract}

Keywords: Seat belt, observation, gender, rural road, urban road

\footnotetext{
* Illetişim / Contact: Dr. Burcu Tekeş, Güvenlik Araştırma Birimi, Psikoloji Bölümü, Orta Doğu Teknik Üniversitesi, Ankara Türkiye.E-Posta /Email: burcutekes@gmail.com Gönderildiği tarihi / Date submitted: 22.05.2018, Kabul edildiği tarih / Date accepted: 27.09.2018

Alıntı / Citation: Duran, E., Ordu, O. ve Tekeş, B. (2018). İstanbul Şile'de Sürücü ve Yolcuların Emniyet Kemeri Kullanımı: Gözlem Çalışması. Trafik ve Ulaşım Araştırmaları Dergisi, 1(2), 16-32.
} 


\section{İstanbul Şile’de Sürücü ve Yolcuların Emniyet Kemeri Kullanımı: Gözlem Çalışması}

Dünya Sağlık Örgütü'nün (DSÖ) 2015 yılında 180 ülkede yaptı̆̆ı bir araştırmaya göre her sene yaklaşık olarak 1.2 milyon insan trafikte hayatını kaybetmektedir. Yapılan araştırmalarda yaşanan ölüm ve kazaların çoğunun ekonomik açıdan yoksul ülkelerde, 15-29 yaş arasındaki kişilerce gerçekleştirildiği görülmektedir (DSÖ, 2015). Dünya nüfusu ve araç sayısının artmasıyla oluşan kazalarda her dokuz saniyede bir trafik kazası gerçekleşmekte ve her on üç saniyede bir kişi de trafik kazası sonucu hayatını kaybetmektedir (DSÖ, 2009a). Bu kayıplar güvenli bir sürüş için trafik güvenliği kavramının önemini ortaya koymaktadır. Kazaları önlemek ve kaza yapan araçlardaki hasar şiddetini minimum seviyeye indirmek amaciyla birtakım güvenlik tedbirleri alınmaktadır. Bu güvenlik tedbirlerinin en önemlilerinden biri olan emniyet kemerinin kaza anında sürücü ve yolcuların en az zararla kurtulmalarını sağladığı söylenebilmektedir.

Emniyet kemeri, kaza anında sürücü ve yolcularda oluşabilecek firlama ve çarpışma etkilerini en aza indirerek, ölüm ve yaralanma riskini azaltıp, sürücü ve yolcuların en ufak hasarla kurtulmalarını sağlamak amacıyla geliştirilmiş bir güvenlik önlemidir (Diyar ve Kurt, 2006; Keskin, 2013; Çukurca, 2010). Yapılan çalışmalar, emniyet kemeri kullanımının ölüm ve yaralanma riskini azaltmadaki önemini vurgular niteliktedir (Şimşekoğlu, 2009; Emniyet Genel Müdürlüğü (EGM), 2009; Keskin, 2013; Tekyol, 2017). Örneğin; Amerikan Ulusal Karayolu Trafik Güvenliği İdaresi (NHTSA) tarafından yapılan bir çalışmada hava yastığı ile beraber kullanılan emniyet kemerinin ciddi kafa çarpmalarının \% 75'ini, ciddi gögüs yaralanmalarının ise \% 66'sını önlemede koruyucu bir faktör olarak etkisi ve işlevi açıkça görülmüştür.

Gelişmişlik düzeyi, ekonomik durum veya eğitim düzeyi gibi faktörlerdeki farklılaşmalar sebebiyle emniyet kemeri kullanım oranlarının dünya genelinde karşılaştırılması zordur. Yapılan bir araştırmaya göre Fransa \% 99, Japonya \% 99 ve Almanya \% 98 oranında emniyet kemeri kullanılırken, İtalya \% 63, Fas \% 60 ve Arjantin \% 50 oranında emniyet kemeri kullanmaktadır (Uluslararası Trafik Güvenliği ve Veri Analiz Grubu [IRTAD], 2018). Avrupa Ulaştırma Güvenliğgi Kurulu'nun 2015 yılındaki raporuna göre emniyet kemeri kullanım oranları İsviçre \% 93, İspanya \% 66, İtalya \% 44, Romanya \% 16 şeklindedir. (Uluslararası Trafik Güvenliği ve Veri Analiz Grubu [IRTAD], 2015). Emniyet kemeri kullanımı düşük olan ülkeler; ekonomik düzeyin düşük olması, sağlık ve eğitim alanlarında eksikliklerin olması gibi temel ortak özellikler göstermektedirler (Şimşekoğlu, 2009; Vivoda, Eby ve Kostyniuk, 2004). Bunun dışında EGM'nin 2016 yılında Türkiye genelinde yaptığ kemeri kullanım ortalaması \% 50.1, ön koltuk yolcularının kemer kullanım ortalaması ise \% 40.6 olarak bulgulanmıştır. Türkiye'de emniyet kemeri kullanımının bu kadar düşük olması, konu ile ilgili yapılacak çalışmalar ve geliştirilecek müdahale çalışmalarının önemini ortaya koymaktadır. Değinildiği üzere, emniyet kemerinin kazaları engelleyici ve/veya şiddetini azaltıcı özelliği güvenlik adına önemli bir yere sahiptir. Söz konusu araştırmada özellikle kaza ve kayıpların sık yaşandığı pilot bir bölgede yürütülen gözlem çalışması ile emniyet kemeri kullanım sıklığına ilişkin bilgi edinilmesi, ayrıca farklı gözlem noktalarından elde edilecek bilgilerin karşılaştırılması ile de kemer kullanımının bölge farkı gösterip göstermediğinin incelenmesi amaçlanmaktadır.

\subsection{Emniyet Kemeri Kullanımını Etkileyen Faktörler}

Değinildiği üzere, emniyet kemeri etkililiği defalarca kanıtlanmış bir güvenlik önlemi olmasına karşın, bazı bölgelerde halen olması gereken yaygınlıkta kullanılmamaktadır. Yapılan çalışmalarda araç tipi, aracın kullanım amacı, yaş, cinsiyet, araç kullanılan bölgenin nüfus yoğunluğu, araç içi oturma pozisyonu, 1rk, gelir düzeyi, eğitim düzeyi ve araç kullanılan zaman

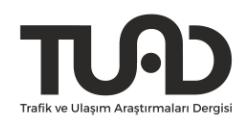


(gündüz veya gece) gibi çok çeşitli faktörlerin sürücülerin emniyet kemeri kullanımlarını etkilediği görülmektedir (Vivoda ve Eby, 2011).

Emniyet kemeri kullanımı üzerinde etkisi olan faktörler demografik, durumsal, çevresel ve psikolojik faktörler olarak sınıflandırılabilir. Etkililiği en sık kanıtlanmış demografik faktörler olarak yaş ve cinsiyet ele alındığında, genç ve erkek sürücülerin daha az kemer kullandığ 1 bilinmektedir (Chliaoutakis, Gnardellis, Drakou, Darviri ve Sboukis, 2000). Durumsal faktörlere örnek gösterilebilecek olan araç tipi, genellikle araç büyüklüğü ile ters orantılı bir emniyet kemeri kullanımına işaret etmektedir (Nitzburg ve Knoblauch, 2004). Buna göre büyük ve yüksek araçlar kullanmak, kişilerde emniyet kemeri kullanımının gereksiz olduğu yönünde hatalı bir güven duygusu oluşturabilmekte ve kemer kullanımı üzerinde olumsuz bir etkide bulunabilmektedir. Aracın kullanıldığı yol tipi veya zamanı, emniyet kemeri kullanımı üzerinde etkili olabilecek çevresel faktörlere örnek gösterilebilir. Buna göre geceleri gündüze göre (Chaudhary, Alonge ve Preusser, 2005) ve kirsalda kentsele göre (Boyle ve Lampkin, 2008) daha az emniyet kemeri kullanılmaktadır.

Psikolojik faktörlerin etkisi incelendiğinde, kişilerin emniyet kemerine yönelik olumsuz tutum ve inançlarının kemer kullanımları ile oldukça ilişkili olduğu bilinmektedir (Ekici, 2014; Sümer 2002; Şimşekoğlu ve Lajunen, 2008). Kişilerin emniyet kemeri kullanımları üzerinde etkili olan bir diğer unsurun ise emniyet kemerinin verdiği rahatsızlık hissi olduğu düşünülmektedir. Emniyet kemerinin hareketi kısıtlaması, doğru konumlandırılmamış koltuk ayarı sonucu oluşan rahatsızlık ve kaza sonrasında kişilerin araç içerisinde sıkışma korkuları kemer kullanımını azaltan nedenler arasındadır (Chliaoutakis ve ark., 2000; Şimşekoğlu ve Lajunen, 2008; Şimşekoğlu, 2011). Yapılan bir çalışmada (Chliaoutakis ve ark., 2000), emniyet kemeri kullanımı üzerinde olumlu etkisi olan psikolojik değişkenler taklit, öz-koruma ve yasal zorunluluk olarak belirlenirken, negatif etkisi olan bir faktör olarak emniyet kemerinin yarattığ 1 rahatsızlık gösterilmiştir.

Sürücülerin özsaygı düzeylerinin düşük ve saldırganlık düzeylerinin yüksek olmasının da emniyet kemeri kullanımları üzerinde negatif bir etkisinin olduğu bilinmektedir (Javadi ve ark., 2015). Benzer şekilde, ebeveyn olmak, yaşça daha büyük olmak (Chliaoutakis ve ark., 2000; Javadi ve ark., 2015) ve emniyet kemeri kullanımının alışkanlık haline getirilmesi (Şimşekoğlu ve Lajunen, 2008) gibi faktörler ise daha yüksek kullanıma yol açmaktadır.

Söz konusu çalışmada yukarıda değinilen faktörlerden gözlem ile ölçülmeye uygun olan tüm faktörlerin çalışmaya dahil edilmesi amaçlanmıştır. Bir istisna olarak gündüz ve gece emniyet kemeri kullanımı farkı fiziksel koşullar mümkün olmadığından çalışmaya dahil edilememiş ve tüm çalışma gündüz yapılan gözlemler ile tamamlanmıştır. Bu çalışmada, sürücülerin emniyet kemeri kullanımları üzerinde etkisi olduğu düşünülen faktörlerden yol ve araç tipi, sürücünün cinsiyeti ve araç içi pozisyonu incelenmiştir.

\subsubsection{Kursal ve kentsel yollar}

Ülkemizde Emniyet Genel Müdürlüğ̈ (EGM) tarafından emniyet kemeri kullanımı 18 Haziran 1986 yılında şehirler-arası yollarda ve 1992 yılında da şehir-içi yollarda zorunlu hale getirilmiştir. Emniyet kemeri kullanımına yasal zorunluluğun getirilmesine rağmen kullanım oranlarının hala düşük olduğu gözlenmiş ve şehir içi yollarda emniyet kemeri kullanan sürücülerin oranının sadece 43.6 olduğu bulgulanmıştır (Özkan ve ark., 2016).

Dünya çapında kırsal ve kentsel yollara göre emniyet kemeri kullanımı ile ilgili yapılan çalışmalar incelendiğinde; 2009 yılında ABD' de 50 eyalette yapılan bir çalışmada kırsal yollardaki emniyet kemeri kullanımı kentsel yollardakine göre daha düşük bulunmuştur (Strine ve ark., 2010). Kentsel yollardaki emniyet kemeri kullanımının kırsal yollardan yüksek

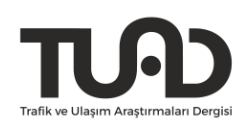


bulunmasında bölgeler arasında farklı algılanan riskin etkili olduğu düşünülmektedir. Kemer kullanımına ilişkin kontrol sıklığının bölgeler arasında farklılık göstermesi ve sürücülerin ceza almaktan kaçınması gibi etkenler de kemer kullanımı üzerinde etkili olabilmektedir. Türkiye'de yapılan çeşitli emniyet kemeri çalışmalarında kentsel ve kırsal yollar arasında oluşabilecek farklar, şehir içi ve şehir dışı yollar olmak üzere sınıflanarak incelenmiştir. Sürücülerin şehir

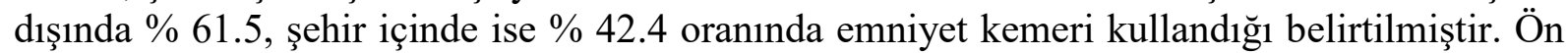
koltuk yolcularının ise şehir dışında \% 52.2, şehir içinde ise \% 31 oranında emniyet kemeri kullandığı bulgulanmıştır (Özkan ve ark., 2016). Kırsal yollarda emniyet kemeri kullanımının, kentsel yollara göre daha düşük olmasının nedeni olarak ekonomik ve politik değişkenler, eğitim seviyeleri ve kültür arasındaki farklılıklar, trafik ağları ve sağlık alanındaki gelişmişlik, gelir düzeyi arasındaki farklılıklar gösterilebilmektedir (Forjuoh, 2003). Bunların yanı sıra kırsal yollarda riskin düşük algılanması, emniyet kemeri hakkındaki bilginin eksik ya da yeterli olmaması, sürüşün kısa mesafeli olması gibi birey düzeyinde açıklamalar da bulunmaktadır (Akay ve Kurt, 2006; Keskin, 2013).

Hem kırsal hem de kentsel bölgelerde emniyet kemeri kullanımının yüksek olduğunu gözlemleyen araştırmalar da bulunmaktadır. 2004 yılında yapılan bir araştırmaya göre Kanada'da kentsel bölgede otomobil sürücülerinin yaklaşık \% 90'1 emniyet kemeri kullanmakta iken, kırsal bölgelerde bu oranı \% 87'dir. Uluslararası Trafik Güvenliği ve Veri Analiz Grubu (IRTAD) aynı çalışmayı 2005 yılında tekrarladığında, Japonya' da otomobil sürücülerinin yaklaşı \% 95'inin hem kentsel hem kırsal bölgede emniyet kemeri kullandığını bulgulamış, Yeni Zelanda'da ise sürücülerin kentsel yollarda \% 92, kırsal yollarda ise \% 95 oranında emniyet kemeri kullandığını bulgulamıştır (IRTAD, 2006). Dünya çapında emniyet kemeri kullanımı ülkelerin gelişmişlik düzeyi, kemer kullanımı konusundaki sosyal pazarlamanın rolü, trafik güvenliği ile ilgili kısa veya uzun dönemli kampanyalar ve hükümetler tarafından ortaya konan yaptırımlar gibi çeşitli nedenlerden dolayı değişiklik gösterebilmektedir (Ekici, 2014).

Tüm bu bilgilerin 1şığında, bu çalışmada emniyet kemeri kullanımının bölgelere göre farklılık gösterip göstermeyeceğinin incelenmesi amaçlanmaktadır. Buna göre daha yüksek hızlarda seyahat eden sürücülerin kendilerini güvene almak istemeleri, trafik memurlarının otobanlardaki emniyet kemeri kontrollerinin yoğun olması ve bu kontrolleri elektronik denetim sistemleri yardımıyla yaygınlaştırmış olmaları gibi sebeplerin, otobanda emniyet kemeri kullanım oranının diğer gözlem noktalarına göre daha yüksek olmasına yol açabileceği düşünülmektedir. Benzer şekilde, kırsal bölgedeki kontrol sıklığının az olması, sürüşlerin genellikle kısa mesafeli olması, kemer kullanmama alışkanlığı ve kırsal bölgelerde genellikle emniyet kemeri uyarı sistemi olmayan eski araçların kullanılması gibi sebeplerle, belirlenen bölgeler (otoban, kırsal, kampüs girişi, kampüs içi) arasında emniyet kemeri kullanım oranlarında farklılık olması beklenmektedir. Kampüs girişi ve kampüs içinde yapılan gözlemlerde de genç sürücülerin yoğunlukta olmaları ve üniversite öğrencilerinin okul ve konaklama yerleri arasındaki mesafenin kısa olması gibi sebeplerle emniyet kemeri kullanımının az olması beklenmektedir.

\subsubsection{Araç tipi}

Araştırmada ele alınan faktörlerden biri de kullanılan araç tipinin emniyet kemeri kullanımı ile ilişkisidir. Türkiye genelinde 77 ilde yapılan bir araştırmada araç tipinin emniyet kemeri kullanımı ile ilişkili olduğu görülmektedir. Otomobil sürücülerinin emniyet kemeri kullanım oranlarının binek araçlarda $\% 57.9$, taksilerde $\% 41.7$, minibüslerde $\% 39.3$, otobüslerde $\% 34.3$ ve kamyonlarda \% 27.2 olduğu görülmektedir. Bu oranlar ön koltuk yolcuları için binek araçlarda $\% 48.8$, taksilerde $\% 34.2$, minibüslerde $\% 21.2$, kamyonlarda $\% 20.8$ ve otobüslerde \% 13.5 şeklinde değişiklik göstermektedir (Özkan ve ark., 2016).

\section{TQD}


Türkiye genelinde şehir içinde emniyet kemeri kullanımının en yüksek \% 48.8 ile binek araçlarda, en düşük kullanımın ise \% 19.4 ile otobüslerde olduğu görülmektedir. Şehir dışında ise en yüksek oranın \% 72.9 ile binek araçlarda, en düşük oranın ise \% 29.1 ile kamyonlarda olduğu görülmektedir (Özkan ve ark., 2016). Buna göre daha çok ağır (minibüs, kamyon, otobüs) araçlarda binek araçlara göre düşük kemer kullanımı görülmektedir. Araç tipine göre değişen konfor ve emniyet kemerinin konforsuzluğu gibi etkenler kemer kullanımının düşmesine neden olarak gösterilebilir (Akay ve Kurt, 2006). Ayrıca ticari araç, kamyon ve otobüslerde profesyonel sürücülerin hissettikleri zaman baskısının hızlı ve aceleci tavırlara, bunun da emniyet kemeri takmayı unutabilmelerine yol açabileceği düşünülmektedir (Dilmaç, Çakar, Kulaksızoğlu ve Şirin, 1998). Ticari araç ve otobüslerdeki düşük kemer kullanımının bir diğer sebebi ise 2014 yılından önceki kanunda emniyet kemeri kullanımının zorunlu olmayış1 gösterilebilir. 2014 yılında EGM'nin yayınladığı yönetmelikle beraber otobüslerdeki yolcu koltuklarında, asker ve polislere, devlet büyüklerinin güvenliğini sağlayan ekiplere, ambulans şoförlerine ve şehir içinde yolcu taşıyan taksi, dolmuş, otobüs gibi araçlara, sürücü ve yolculara emniyet kemeri kullanımı zorunlu hale gelmiştir (Özkan ve ark., 2015a). Son olarak ticari araç, kamyon ve otobüslerdeki bu oranın düşüklüğünü açıklayan bir diğer neden ise tecrübe etkisidir. İlgili alanyazında artan kilometrenin kemer kullanımı ile ters yönde ilişkili olduğuna ilişkin bulgular bulunmaktadır (Chliaoutakis ve ark., 2000). Buna göre sürücülerin sahip olduğu tecrübenin kişide oluşturduğu aşırı güvenin emniyet kemeri kullanmama davranışına neden olduğu düşünülmektedir. Ticari araç, kamyon ve otobüs sürücülerinin aynı güzergâh üzerinde uzun süre araç kullanmaları, yol üzerindeki trafik denetimlerinin nerede ve ne sıklikta olduğundan haberdar olmalarını sağlayabilmektedir. Özellikle emniyet kemeri kullanmayan sürücülerin denetimlerden haberdar olması ceza alma korkusunu ortadan kaldıracağından kemer kullanımını azalttığı düşünülmektedir (Şimşekoğlu, 2005). Tüm bu bilgilerin 1şığında, farklı araç tiplerinin de çalışmaya dahil edilmesinin alanyazına katkı sağlayacağı düşünülmektedir. Alanyazınla tutarlı olarak, emniyet kemeri kullanımının özel otomobil sürücüleri arasında, profesyonel sürücülerin kullandığı taksi, minibüs ve otobüs gibi araçlara göre daha yaygın olması beklenmektedir.

\subsubsection{Cinsiyet.}

Emniyet kemeri kullanımı üzerinde etkisi en kolay gözlemlenebilen demografik değişkenlerden biri cinsiyettir. Cinsiyetler arasındaki farka bakıldığında kadınların, erkeklere göre daha fazla emniyet kemeri kullandıkları görülmektedir (Chliaoutakis ve ark., 2000; Shaaban, 2018; Şimşekoğlu ve Lajunen, 2008). Bu farkında belirginleşmesinin en önemli sebebi olarak trafikte kadınların erkeklere göre ihlale daha az yatkın olmaları gösterilebilir (Reason, Manstead, Stradling, Baxter ve Campbell, 1990). Erkek sürücülerin heyecan arama (Jonah, 1997) ve risk alma (Chaudhary, Solomon ve Cosgrove, 2004) düzeylerinin daha yüksek oluşu, emniyet kemeri kullanım oranlarının düşük olması ile de ilişkili görülmektedir. Bununla birlikte, emniyet kemeri kullanmama sebepleri üzerine yapılan çalışmada kadınlar ve erkeklerin kemer kullanmama sebepleri açısından birbirlerinden farklılaştıkları, erkeklerin emniyet kemerini kadınlar kadar faydalı görmediği bulunmuştur (Calisir ve Lehto, 2002).

Cinsiyet ve yaşın etkisi beraber incelendiğinde, genç erkek sürücülerin alanyazında sıklıkla ilişkili bulundukları yüksek risk alma düzeyi ve heyecan arayışı gibi özelliklerin yanı sıra, yaş döneminin de beraberinde getirdiği bazı bilişsel özelliklerin (akıl yürütme, düşünme ve problem çözme) emniyet kemeri kullanımını olumsuz yönde etkilediği bilinmektedir (Ekici, 2014; Keskin, 2013; Şimşekoğlu, 2009).

Bu çalışmada da değinilen çalışmalarla tutarlı olarak erkek sürücüler arasında emniyet kemeri kullanımının kadın sürücülerden daha düşük olması beklenmektedir. Erkek sürücülerin trafikteki risk alma davranışlarının kadın sürücülerden daha yüksek olması böylece kadın

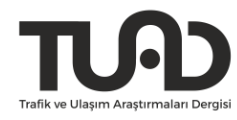


sürücülerin trafikte kurallara uyma davranışlarının, erkek sürücülere göre daha yüksek olması gibi sebeplerle, erkek sürücülerin kadın sürücülere göre daha az oranda emniyet kemeri kullanmaları beklenmektedir.

\subsubsection{Araç içi pozisyon}

Emniyet kemeri kullanımı ile ilgili yapılan birçok çalışmada, sürücülerin yolculara göre daha yüksek oranda emniyet kemeri kullandığı bulgusu desteklenmektedir (Özkan ve ark., 2014; 2015b; 2016; Chaffe, Leaf ve Solomon, 2006; Vivoda ve Eby, 2011). Bununla beraber, sürücü ve yolcuların emniyet kemeri kullanımları birbirleri ile oldukça ilişkili görülmektedir. Buna göre araçta sürücünün emniyet kemeri kullandığı durumlarda, yolcular da daha fazla kemer kullanma eğilimindedir (Kim ve Kim, 2003). Bu eğilim beraber yolculuk eden kişilerin benzer özellikler, tutum ve davranışlar paylaşması ile açıklanabileceği gibi, yolcuların aracın kontrolüne sahip olan kişi olan sürücüye uyma davranışı göstermesi ile de açıklanabilir.

Yolcular arasındaki emniyet kemeri kullanımları arasındaki farka bakıldığında, arka koltuk yolcularının en az emniyet kemeri kullanma oranına sahip olduğu görülmektedir. Oranlar arasındaki bu farklılığın sebebi olarak, arka koltukta yolculuk etmenin yolcularda hatalı bir güven algısı yaratması gösterilebilir (Jermakian ve Weast, 2017). Ancak yapılan çalışmalar arka koltukta da emniyet kemeri kullanımının önemini vurgulamaktadır. Norveç’te yapılan bir çalışmada, bir kaza anında araç içi yaralanmalarının \% 60'ını kafa travmalarının oluşturduğunu ve sürücü, ön ve arka koltuk yolcularının kazadan benzer şekilde fiziksel hasar aldıklarını bulgulamıştır. Bununla birlikte, arka koltukta emniyet kemeri olmadan yolculuk eden bir kişi, bir çarpışma anında araç içinde savrulacağından, diğer yolcular ve sürücü için bir risk faktörü de oluşturmaktadır (DSÖ, 2009b).

Türkiye'de en güncel olarak ve en geniş çapta yapılan emniyet kemeri gözlem çalışması, EGM ve Orta Doğu Teknik Üniversitesi tarafından 2016 yılında 71 ilde yapılmış olan emniyet kemeri gözlem çalışmasıdır (Özkan ve ark., 2016). Söz konusu çalışma Türkiye'de emniyet kemeri kullanımı konusunda yapılmış en kapsamlı çalışma olmakla beraber, arka koltuk yolcuları çalışmaya dahil edilememiştir. Bu araştırmada yapılan gözleme arka koltuk yolcuları da dahil edilerek, alanyazına farklı bir katkı daha sağlanması amaçlanmıştır. Yukarıda değinilen bilgiler göz önünde bulundurulduğunda, çalışmada sürücüler arasında emniyet kemeri kullanımının daha sık olması ve yolcular ile sürücülerin emniyet kemeri kullanımlarının ilişkili olması beklenmektedir. Arka koltuk yolcularının emniyet kemeri kullanımlarının sürücü ve ön koltuk yolcuları ile ilişkisine dair bir çalışma bulunmadığından, söz konusu bulgu keşifsel olarak incelenecektir.

\subsection{Amaç}

$\mathrm{Bu}$ çalışmanın amacı, araç sürücüleri ve yolcularının emniyet kemeri kullanımına etki eden kentsel ve kırsal yol ayrımı, araç tipi, cinsiyet ve araç içi pozisyon faktörlerinin gözlenmesidir. $\mathrm{Bu}$ amaçla, Şile bölgesinde, Işık üniversitesi kampüs içi, kampüs girişi, üniversitenin üzerine konumlandığı Şile otobanı ve Şile kırsalı yollarında emniyet kemeri gözlem çalışmaları yapılması hedeflenmiştir. Şile yolunun trafik kazaları açısından riskli bir bölge olması ve üniversite öğrencilerinin sıklıkla kazaya karışmaları çalışmanın özellikle bu bölgede yapılmasının sebebi olarak gösterilebilir. Şile-İstanbul yolunun büyük alt yapı faaliyetlerinin ve çeşitli inşaatların güzergahında kalması sebebiyle damperli kamyonların fazlalığı, yolların bozuk olması, bölgenin İstanbul içine göre daha fazla yağış alması ile yolların ıslak ve kaygan olması ve son olarak üst geçitlerin ve yaya yollarının az ya da yetersiz olması gibi sebepler bu bölgede gerçekleşen oldukça fazla sayıda kazayı açıklar niteliktedir (Ayazsın, 2017; Çoban, 2017; DHA, 2016; Kırcalı, 2016). Ayrıca, Şile-İstanbul otobanı üzerinde bulunan Işık Üniversitesi öğrencilerinin sıklıkla ölüm ve yaralanmalar ile sonuçlanan trafik kazalarına

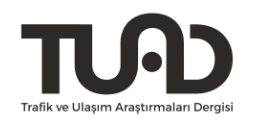


karışıyor olmaları sebebiyle üniversite ve yakın çevresi gözlem çalışmasının merkezi olarak belirlenmiştir (“Şile'de feci kaza”, 2013; "Şile'de kaza”, 2010). Bu sebeple söz konusu bölgede öncelikle bahsi geçen faktörler açısından emniyet kemeri kullanımlarının dağılımlarının incelenmesi amaçlanmaktadır. İlgili alanyazın ile tutarlı olarak, otobanda, özel otomobil kullanıcıları arasında, kadınlarda ve araç sürücülerinde emniyet kemeri kullanımının diğer gruplara göre daha yaygın olacağı beklenmektedir. Bunun yanı sıra, cinsiyet ve araç kullanılan bölgenin ilişkisine göre emniyet kemeri kullanımının keşifsel olarak incelenmesi amaçlanmaktadır. Son olarak, sürücü ve yolcuların emniyet kemeri kullanımlarının birbirileri ile pozitif yönde ilişkili olduğu bilinmekle beraber, arka koltuk yolcularını da içeren bir çalışmaya rastlanmamıştır. Bu sebeple, sürücü, ön ve arka koltuk yolcularının emniyet kemeri kullanımlarının birbirleri ile ilişkisinin incelenmesi amaçlanmaktadır.

\section{Yöntem}

\section{1. Örneklem}

Bu çalışma kapsamında her bölgeden 100 araç olacak şekilde toplam 400 araç gözlemlenmiştir (Kampus-içi, Kampüs girişi, Şile Otobanı, Şile Kırsal). Araç sürücülerinin cinsiyet ve araç tipine göre frekans analizi Tablo 1'de sunulmuştur. Gözleme alınan otomobil sürücülerinin 336'sı (\% 84) erkek ve 64'ü de (\% 16) kadındır. Detaylı olarak bakıldığında, kampüs girişi araç kullanan sürücülerin 74'ü erkek (\% 84.1), 14'ü kadındır (\% 15.9). Kampüs içi araç kullananların 80'i erkek (\% 78.4), 22'si de kadındır (\% 21.6). Otobanda araç kullananların 85'i erkek (\% 83.3), 17'si de kadındır (\% 16.7). Kırsalda araç kullananların 97'si erkek (\% 89.8), 11'i de kadındır (\% 10.2). Katılımcıların dağılımı Tablo 1'de gösterilmektedir.

Tablo 1. Cinsiyet ve araç tipine göre yapılan frekans analizi

\begin{tabular}{llccc}
\hline & & Frekans & Yüzde (\%) & Toplam \\
\hline Kampüs girişi & Erkek & 74 & 84 & \multirow{2}{*}{88} \\
& Kadın & 14 & 15.9 & \\
Kampüs içi & Erkek & 80 & 78.4 & \multirow{2}{*}{102} \\
& Kadın & 22 & 21.6 & \\
Otoban & Erkek & 85 & 83.3 & \multirow{2}{*}{102} \\
& Kadın & 17 & 16.7 & \\
Kırsal & Erkek & 97 & 89.8 & \multirow{2}{*}{108} \\
& Kadın & 11 & 10.2 & \\
\hline
\end{tabular}

\section{2. İşlem}

Bu çalışma, İstanbul ilinin Şile ilçesinde bulunan Işık Üniversitesi (kampüs girişi, kampüs içi), İstanbul-Şile karayolu (Otoban) ve Şile kırsalı olmak üzere dört ayrı noktada sürücülerin ve yolcuların emniyet kemerinin takılı olup/olmadığı gözlemlenerek yapılmıştır. Eby (2000; 2011)'ye göre bir gözlem çalışmasının oluşturulmasında en önemli unsurlardan biri seçkisiz bir yöntem kullanılmış olmasıdır. Kemer kullanan ve kullanmayan kişilerin çalışmaya dahil edilme olasılıklarının aynı olması hedeflendiğinden, Şile otobanı, Şile kırsalı ve kampüs içindeki gözlem noktaları seçkisiz olarak belirlenmiştir, ancak trafiğin doğal bir şekilde akıp akmadığı ve sürücüleri engelleyecek bir şeyin olup olmadığı kontrol edilmiştir. Gözlemler herhangi bir yanlılık olmaması adına sabah, öğle ve akşam olmak üzere günde üç defa yapılmış ve verinin tamamı dört günde toplamda yirmi dört saat süren gözlem sonucunda toplanmıştır. Gözlemciler özellikle arka koltuk yolcularının emniyet kemeri kullanımlarını da gözlemleyebilmek adına bir adet kamera ve tripot yardımıyla yoldan geçen araçları video kaydına almıştır. Gözlemciler tarafından araçların plakasının son üç hanesi alınarak bir kontrol listesine kaydedilmiş, böylece

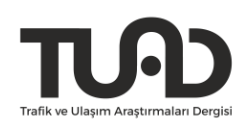


aynı aracın iki defa gözlemlenmesinin önüne geçilmesi amaçlanmıştır. Ayrıca hız, camdaki film kaplaması, iki arabanın yan yana durması, cam önündeki eşyalar gibi sebeplerle görüntünün engellendiği araçlar çalışmaya dahil edilmemiştir. EGM (2016) raporuna göre İstanbul dişında emniyet kemeri kullanımı oranı \% 60 civarındadır. Eby (2000)'nın hesaplamasına göre, yüzde 2'lik bir hata payı için nüfusun \% 60'ının emniyet kemeri kullandığı bir bölgede, en az 257 kişilik bir gözlemde bulunmak gerekmektedir. Bu sebeple yapılan gözlem sayısının bu rakamdan büyük olması hedeflenmiştir.

\section{Bulgular}

Çalışmada emniyet kemerine etki eden faktörleri (bölge, araç pozisyonu, cinsiyet, araç tipi) görmek amacıyla ki-kare analizi, yolcular ve sürücülerin emniyet kemeri kullanımları arasındaki ilişkiyi görmek amacıyla da korelasyon analizi yapılmıştır.

Yapılan ki-kare analizi sonucunda incelenen tüm değişkenlerin dağılımı anlamlıdır. Buna göre en fazla emniyet kemeri kullanımı sırasıyla otoban, kampüs içi, kampüs girişi ve kırsalda görülmektedir. Araç içi pozisyonun emniyet kemeri kullanımı ile ilişkisine bakıldığında, en yüksek kullanım oranının sırasıyla araç sürücüleri, ön koltuk yolcuları ve arka koltuk yolcularında olduğu görülmektedir. Cinsiyetin dağılımına bakıldığında, kadınlar erkeklere göre daha fazla oranda emniyet kemeri kullanmaktadırlar. Son olarak, farklı araç tiplerinin emniyet kemeri kullanım oranları incelendiğinde emniyet kemeri kullanımının en yaygın olduğu grubun otomobil sürücüleri olduğu görülmektedir. Onları sırasıyla taksi sürücüleri, otobüs sürücüleri ve kamyon sürücüleri takip etmektedir. Yukarıda değinilen değişkenlerin oranları, gözlemlerin sayıları ve analizlerin anlamlılığına ilişkin değerler Tablo 2'de özetlenmiştir.

Tablo 2. Emniyet kemeri kullanmanın cinsiyete, bölgelere ve araç içi pozisyona göre analizi

\begin{tabular}{|c|c|c|c|c|c|c|}
\hline & & \multicolumn{2}{|c|}{ Emniyet Kemeri } & \multirow[b]{2}{*}{$X^{2}$} & \multirow[b]{2}{*}{ Ss } & \multirow[b]{2}{*}{$p$} \\
\hline & & $\begin{array}{c}\text { Var } \\
(\mathrm{N} / \%)\end{array}$ & $\begin{array}{c}\text { Yok } \\
(\mathrm{N} / \%)\end{array}$ & & & \\
\hline \multirow{4}{*}{ Bölgeler } & Kampüs girişi & $35 / 39.77$ & $53 / 60.23$ & \multirow{4}{*}{46.41} & \multirow{4}{*}{3} & \multirow{4}{*}{$.000 * * *$} \\
\hline & Kampüs içi & $44 / 43.14$ & $58 / 56.86$ & & & \\
\hline & Kirsal & $15 / 13.89$ & 93/86.11 & & & \\
\hline & Otoban & $60 / 58.82$ & $42 / 41.18$ & & & \\
\hline \multirow{3}{*}{$\begin{array}{l}\text { Araç içi } \\
\text { pozisyon }\end{array}$} & Şoför & $153 / 38.25$ & $247 / 61.75$ & 387.43 & 1 & $.000 * * *$ \\
\hline & Ön koltuk yolcusu & $69 / 27.49$ & $182 / 72.51$ & 128.12 & 2 & $.000 * * *$ \\
\hline & Arka koltuk yolcusu & $5 / 6.85$ & $68 / 93.15$ & 14.1 & 2 & $.001 * * *$ \\
\hline \multirow{2}{*}{ Cinsiyet } & Kadın & $37 / 57.81$ & $27 / 42.19$ & \multirow{2}{*}{12.00} & \multirow{2}{*}{1} & \multirow{2}{*}{$.001 * * *$} \\
\hline & Erkek & $117 / 34.82$ & $219 / 65.18$ & & & \\
\hline \multirow{4}{*}{ Araç tipi } & Kamyon & $1 / 3.4$ & $28 / 96.6$ & \multirow{4}{*}{34.10} & \multirow{4}{*}{3} & \multirow{4}{*}{$.000 * * *$} \\
\hline & Otomobil & $147 / 45.2$ & $178 / 54.8$ & & & \\
\hline & Taksi & $3 / 17.6$ & $14 / 82.4$ & & & \\
\hline & Otobüs & $3 / 10.3$ & $26 / 89.7$ & & & \\
\hline
\end{tabular}




\subsection{Cinsiyet ve Bölgelere Göre Emniyet Kemeri Kullanımı}

Sürücülerin emniyet kemeri kullanımlarının cinsiyet ve gözlem bölgelerine göre dağılımını belirlemek amacıyla Ki-Kare Bağımsızlık Testi uygulanmış ve genel olarak, kadın sürücülerin emniyet kemeri kullanımının erkek sürücülerin emniyet kemer kullanımından daha yüksek olduğu gözlemlenmiştir. Cinsiyetin farklı bölgelerdeki dağılımına bakıldığında, bütün bölgelerde (Kampüs-içi, Kampüs girişi, Otoban, Kırsal) kadın sürücülerin emniyet kemeri kullanımlarının, erkek sürücülerin kemer kullanımından daha fazla olduğu bulgulanmıştır. Işık Üniversitesi kampüs girişinde araç kullanan erkek sürücülerin \% 35.1'i, kadın sürücülerin ise \% 64.3'ü emniyet kemeri kullanmaktadır. Işık üniversitesi kampüs içinde araç kullanan erkek sürücülerin \% 40' 1 , kadın sürücülerin ise $\% 54.5$ 'i emniyet kemeri kullanmaktadır. Otobanda araç kullanan erkek sürücülerin \% 57.6'sı, kadın sürücülerin ise \% 64.7'si emniyet kemeri kullanmaktadır. Kırsalda araç kullanan erkek sürücülerin \% 10.3'ü, kadın sürücülerin ise \% 45.5'i emniyet kemeri kullanmaktadır. Bununla birlikte her iki cinsiyetin kendi içindeki dağılımları incelendiğinde, kadın sürücülerin farklı bölgelerdeki emniyet kemeri kullanımları arasında anlamlı bir farklılık bulunmazken $\left(\chi^{2}=1.36, p=.716\right)$, erkek sürücülerin emniyet kemeri kullanımları bölgelere göre anlamlı bir şekilde dağılmaktadır $\left(\chi^{2}=46.14, p=.000\right)$. Karşılaştırma gruplarının sayıları, yüzdeleri ve anlamlılık düzeyleri Tablo 2 ve 3' de gösterilmektedir.

Tablo 3. Emniyet Kemeri Kullanmanın cinsiyete ve bölgelere göre analizi

\begin{tabular}{clccccc}
\hline \multicolumn{1}{c}{$\begin{array}{c}\text { Emniyet Kemeri } \\
\text { Kullanımı }\end{array}$} & $\begin{array}{c}\text { Kampüs Girişi } \\
(\mathrm{N} / \%)\end{array}$ & $\begin{array}{c}\text { Kampüs İçi } \\
(N / \%)\end{array}$ & $\begin{array}{c}\text { Otoban } \\
(N / \%)\end{array}$ & $\begin{array}{c}\text { Kırsal } \\
(N / \%)\end{array}$ \\
\hline \multirow{6}{*}{ Cinsiyet } & kemeri & Erkek & $26 / 35.1$ & $32 / 40.0$ & $49 / 57.6$ & $10 / 10.3$ \\
& takıyor & Kadın & $9 / 64.3$ & $12 / 54.5$ & $11 / 64.7$ & $5 / 45.5$ \\
& $\begin{array}{l}\text { 2.Emniyet } \\
\text { kemeri }\end{array}$ & Erkek & $48 / 64.9$ & $48 / 60.0$ & $36 / 42.4$ & $87 / 89.7$ \\
& takmıyor & Kadın & $5 / 35.7$ & $10 / 45.5$ & $6 / 35.3$ & $6 / 54.5$ \\
& & \multicolumn{2}{c}{$\chi^{2}(3)_{\text {Erkek }}=46.14, p=.000 ; \chi^{2}(3)$ Kadın $=1.36, p=.716$} \\
\hline
\end{tabular}

\subsection{Araçtaki Pozisyonun Bölgelere Göre Emniyet Kemeri Kullanımı.}

Emniyet kemeri kullanımı ile araçtaki oturma pozisyonu ve gözlem bölgelerinin (sürücü, ön ve arka koltuk) dağılımını belirlemek amacıyla Ki-Kare Bağımsızlık Testi uygulanmış ve genel olarak sürücülerin emniyet kemeri kullanım oranlarının, ön ve arka yolcuların kemer kullanım oranlarından daha yüksek olduğu gözlemlenmiştir.

Araç içindeki pozisyona göre dağılım incelendiğinde hem sürücülerin hem de ön koltuk yolcularının sırasıyla otoban, kampüs içi, kampüs girişi ve en az olarak da kırsalda emniyet kemeri kullandığı bulgusuna ulaşılmıştır. Arka koltuk yolcularının farklı bölgelerdeki emniyet kemeri kullanımı dağılımları arasında anlamlı bir farklılık bulunmamaktadır. Karşılaştırma gruplarının sayıları, yüzdeleri ve analize ilişkin istatistiki değerler Tablo 4' de gösterilmektedir. 
Tablo 4. Farklı gözlem bölgelerinde araçtaki pozisyona göre kemer kullanımı

\begin{tabular}{|c|c|c|c|c|c|}
\hline \multicolumn{2}{|c|}{ Emniyet Kemeri Kullanımı } & $\begin{array}{c}\text { Kampüs } \\
\text { Girişi } \\
(N / \%)\end{array}$ & $\begin{array}{l}\text { Kampüs İçi } \\
(N / \%)\end{array}$ & $\begin{array}{l}\text { Otoban } \\
(N / \%)\end{array}$ & $\begin{array}{l}\text { Kirsal } \\
(N / \%)\end{array}$ \\
\hline \multirow{3}{*}{ Sürücü } & $\begin{array}{l}\text { 1.Emniyet } \\
\text { kemeri } \\
\text { takıvor }\end{array}$ & $36 / 23.5$ & $43 / 28.1$ & $60 / 39.2$ & $14 / 9.2$ \\
\hline & $\begin{array}{l}\text { 2.Emniyet } \\
\text { kemeri } \\
\text { takmiyor }\end{array}$ & $52 / 21.1$ & $59 / 23.9$ & $42 / 17$ & $94 / 38.1$ \\
\hline & & \multicolumn{2}{|c|}{$X^{2}(3)=48,44$} & \multicolumn{2}{|c|}{$p<.001 * * *$} \\
\hline \multirow{3}{*}{$\begin{array}{l}\text { Ön koltuk } \\
\text { yolcusu }\end{array}$} & $\begin{array}{l}\text { 1.Emniyet } \\
\text { kemeri }\end{array}$ & $11 / 15.9$ & $16 / 23.2$ & $37 / 53.6$ & $5 / 7.2$ \\
\hline & $\begin{array}{l}\text { 2.Emniyet } \\
\text { kemeri } \\
\text { takmiyor }\end{array}$ & $29 / 15.9$ & $58 / 31.9$ & $32 / 17.6$ & $63 / 34.6$ \\
\hline & & \multicolumn{2}{|c|}{$X^{2}(6)=57,34$} & \multicolumn{2}{|c|}{$p<.001 * * *$} \\
\hline \multirow{3}{*}{$\begin{array}{c}\text { Arka koltuk } \\
\text { yolcusu }\end{array}$} & $\begin{array}{l}\text { 1.Emniyet } \\
\text { kemeri } \\
\text { takıyor }\end{array}$ & $1 / 20$ & $1 / 20$ & $3 / 60$ & $0 / 0$ \\
\hline & $\begin{array}{l}\text { kemeri } \\
\text { takmiyor }\end{array}$ & $22 / 32.4$ & $12 / 17.6$ & $14 / 20.6$ & $20 / 29.4$ \\
\hline & & & $X^{2}(6)=10.58$ & \multicolumn{2}{|c|}{$p=.102$} \\
\hline
\end{tabular}

\subsection{Sürücü ve Yolcularının emniyet kemeri kullanımları arasındaki ilișkiler}

Araştırmada ayrıca sürücü, ön ve arka koltuk yolcuların emniyet kemeri kullanımları arasında bir ilişki olup olmadığının anlaşılması için korelasyon analizi yapılmıştır. Bunun için öncelikle ön ve arka koltukta yolcusu olan araçlar veriden seçilmiş, yolcusu olmayan araçlar daha doğru sonuçlar elde edilebilmesi açısından analiz dışında bırakılmıştır. Buna göre, araç sürücüsünün emniyet kemeri kullanımı ile ön koltuk yolcusunun emniyet kemeri kullanımı arasında pozitif yönde güçlü bir ilişki bulunmaktadır $(r=.53, p=.000)$. Ayrıca, sürücü ile arka koltuk yolcusunun emniyet kemeri kullanımı arasında pozitif yönde ve orta düzeyde anlamlı bir ilişki bulunmaktadır $(r=.36, p=.000)$. Son olarak, ön ve arka koltuk yolcularının emniyet kemeri kullanımı arasında yine pozitif yönde ve güçlü bir ilişki olduğu bulgulanmıştır $(r=.60, p=$ $.000)$.

\section{Tartışma}

Bu çalışmada, araç sürücüleri ve yolcularının emniyet kemeri kullanımı dağılımları İstanbul ili, Şile ilçesi, Kumbaba mevkiinde bulunan Işık Üniversitesi çevresinde gözlemlenmiştir. Üniversitenin bulunduğu konum gereği otoban üzerinde olması ve öğrencilerin konakladığ 1 kampüs dışındaki özel yurtlara otoban ve kırsal yollar aracılığı ile ulaşılıyor olması bu çalışmanın kampüs dışını da kapsayacak şekilde planlanmasının sebepleri arasındadır. Yukarıda da değinildiği üzere, söz konusu bölge çeşitli büyük alt yapı çalışmalarının güzergahında kaldığından, çok sayıda hafriyat kamyonu tarafından kullanılmaktadır. Bunun

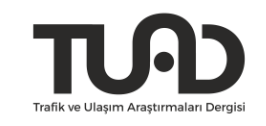


dışında araç trafiğinin azlığı ve üniversiteye bağlı genç nüfusun varlığı gibi sebepler hızlı araç kullanımı ve buna bağlı kazalar ile ilişkili görülmektedir (DHA, 2016). Bu sebeple, bölgede emniyet kemeri kullanımının dağılımının incelenmesi, bu kazaların ve kazalara bağlı kayıpların azaltılması için önemli görülmüştür.

Analizler sonucunda emniyet kemerinin en fazla otobanda, en az ise kırsal yollarda kullanıldığ gözlemlenmiştir. Bu bulgu, otobandaki denetimin diğer bölgelere göre daha sık olması ile açıklanabilir. Risk-denge teorisine göre risk arttıkça kişiler kendilerine bir denge unsuru oluşturarak riski azaltmaya çalışırlar (Wilde, 1998). Bu duruma göre; otobandaki sürücülerin hızları arttıkça kendilerine güvence oluşturmak için emniyet kemerini bir denge unsuru olarak görüp, canlarını güvence altına almak isteyebilecekleri ve böylece riski azalttıklarına inandıkları düşünülebilir. Çalışmada beklendiği şekilde, kırsalda emniyet kemerinin diğer bölgelerden daha düşük oranda kullanıldığı bulunmuştur. Kırsal bölgede kullanım sıklığının düşük olması üzerinde, alanyazınla tutarlı şekilde, sürücülerin gidecekleri mesafenin az olması, sürücüde kemerin oluşturduğu konforsuzluk hissi ve emniyet kemeri kontrollerinin az olmasi gibi nedenlerin etkili olduğu düşünülmektedir (Akay ve Kurt, 2006; Chliaoutakis ve ark., 2000; Çukurca, 2010; Keskin, 2013; Şimşekoğlu, 2011; Şimşekoğlu ve Lajunen, 2008). Son olarak, Işık Üniversitesi kampüs içi ve kampüs girişi emniyet kemeri kullanımı incelendiğinde kampus içinde daha fazla emniyet kemeri kullanıldığı görülmüştür. İlginç bir bulgu olarak, üniversiteye otobandan gelen sürücülerin kampüs girişine yaklaştıklarında emniyet kemerini çıkardıkları gözlemlenmiştir. Bu nedenle kampüs girişinde, kampüs içindeki emniyet kemeri kullanımından daha düşük bir oran elde edildiği düşünülmektedir. Ayrıca sürücülerin gözlemcileri fark etmesinin de kampüs içindeki kullanıma etki edebileceği tahmin edilmektedir. Araç içi pozisyonun emniyet kemeri kullanımı ile ilişkisine bakıldığında, en yüksek kullanım oranının sırasıyla araç sürücüleri, ön koltuk yolcuları ve arka koltuk yolcularında olduğu görülmektedir. Sürücü ve ön koltuk yolcuları arasındaki bu fark konu ile ilgili yapılmış önceki çalışmalarla tutarlı görünmektedir (Özkan ve ark., 2016). Arka koltukta emniyet kemeri kullanımının dağılımına ilişkin çok fazla çalışma olmamakla beraber, sürücü ve yolculara oranla çok daha az oranda kemer kullanıldığı bilinmektedir (DSÖ, 2009b). Bu çalışmada bu dağılım doğrulanmıştır. Arka koltuk yolcularının düşük oranda emniyet kemeri kullanıyor olmaları, arka koltukta riskin düşük algılanması, emniyet kemeri kullanımının alışkanlık haline getirilememesi, emniyet kemerinin yarattığ 1 rahatsızlık hissi (Jermakian ve Weast, 2017) gibi sebeplerle ilişkili olduğu kadar, eski model araçlarda kemer ikaz sisteminin olmaması ve yolcuların sürücüye aşırı güvenmesi gibi sebeplerle de açıklanabilir (Çukurca, 2010; Keskin, 2013). Bu çalışmada sürücü, ön ve arka koltuk yolcularının emniyet kemeri kullanımlarının birbirleri ile oldukça ilişkili olduğu görülmüştür. Özellikle, sürücü ve ön koltuk yolcuları arasındaki pozitif yöndeki ilişki, birinin emniyet kemeri kullanımı arttıkça diğerinin de kemer kullanımının artacağını güçlü bir şekilde öngörmektedir. İlginç bir şekilde, arka koltuk yolcularının emniyet kemeri kullanımları, ön koltuk yolcularının emniyet kemeri kullanımları ile, sürücülerin emniyet kemeri kullanımları ile olandan daha güçlü ilişki içindedir. Diğer bir deyişle, sürücünün kemer kullanımı arka koltuk yolcusunun da emniyet kemeri kullanımı ile olumlu ilişki içindedir ancak, ön ve arka koltuk yolcularının emniyet kemeri kullanımları arasında daha güçlü bir ilişki bulunmaktadır. Bu bulgu temel sosyal psikolojik eğilimler olan benzerlik ve uyma davranışları ile açıklanabilir (Taylor, Peplau ve Sears, 2010). Araçta benzer yolcu pozisyonunda bulunmalarının, ön ve arka koltuk yolcularının birbirlerine daha fazla uyma davranışı göstermelerine yol açtığı varsayılabilir.

Sürücü ve ön koltuk yolcularının emniyet kemeri kullanımları farklı bölgelerdeki emniyet kemeri kullanım oranları ile tutarlı görünmektedir. Buna göre sürücüler ve ön koltuk yolcuları yine en sık otobanda kemer kullanırlarken, bunu sırasıyla kampüs içi, kampüs girişi ve kırsal takip etmektedir. Burada farklı bir bulgu olarak, arka koltuk yolcularının emniyet kemeri

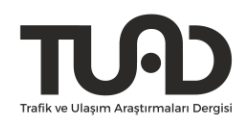


kullanımlarının araç kullanılan bölgeye bağlı olmadığı görülmüştür. Buna göre arka koltukta kemer kullanım oranları otoban, kırsal, kampüs içi veya girişinde değişmemektedir. Burada daha farklı değişkenlerin etkisi olduğu düşünülmektedir. Buna göre, unutma ya da rahatsız olma gibi emniyet kemeri kullanmama sebepleri tüm yolcular ve araç sürücüleri tarafından paylaşılabilirken, arka koltuk yolcularında diğer gruplardan farklı olarak arka koltuğun daha güvenli olduğu, bu yüzden emniyet kemerine ihtiyaç olmadığı yönünde bir inanç olduğunu görülmektedir (Jermakian ve Weast, 2017).

Cinsiyetin emniyet kemeri kullanımı üzerindeki dağılımına bakıldığında, kadınların erkeklere göre daha fazla oranda emniyet kemeri kullandıkları görülmektedir. Kadın sürücülerin emniyet kemeri kullanımlarının erkek sürücülerden daha fazla olmasının nedenleri arasında; yüksek risk algısına sahip olmaları, erkek sürücülerin ihlale daha yatkın olmaları, genç erkek sürücülerin dikkat, planlama, akıl yürütme gibi beynin kortikal işlevlerinden sorumlu olan prefrontal bölgenin genç yetişkinlik dönemine kadar gelişimini geç tamamlaması ve genç erkek sürücülerin risk alma davranışlarının kadın sürücülerden daha çok olması gibi sebepler gösterilebilir (Ekici, 2014; Şimşekoğlu, 2009; Keskin, 2013). Her iki cinsiyetin farkl1 bölgelerdeki emniyet kemeri kullanımları incelendiğinde, erkekler arasındaki farkın yukarıda değinilen çerçeve ile tutarlı olduğu görülürken, kadınlar arasında bölgelere göre kemer kullanımı farklılaşmamıştır. Bu bulgu kadınların trafikte kural ihlaline erkeklere göre daha az yatkın olması ile açıklanabilir (Diaz, 2002). Buna göre erkeklerin emniyet kemeri kullanımı üzerinde nerede araç kullandıkları etkili bir faktör iken, kadınların emniyet kemeri kullanımları üzerinde bir etkisi bulunmamaktadır. Diğer bir deyişle, kemer kullanmayı alışkanlık haline getiren bir kadın sürücü her ortamda kemer kullanmaktadır.

Son olarak, farklı araç tiplerinin emniyet kemeri kullanım oranları incelendiğinde emniyet kemeri kullanımının en yaygın olduğu grubun otomobil sürücüleri olduğu görülmektedir. Onları sırasıyla taksi sürücüleri, otobüs sürücüleri ve kamyon sürücüleri izlemektedir. Dağılımdaki farklılaşma profesyonel sürücülerin daha az emniyet kemeri kullandığı bulgusunu destekler niteliktedir. Profesyonel sürücülerin uzun saatler boyu araç kullanmaları sonucu emniyet kemerine bağlı artan rahatsızlık hissi, çok fazla deneyime bağlı gelişen güven duygusu veya beş y1l öncesine kadar var olan, profesyonel sürücülerin kemer kullanma zorunluluğunun olmayışı gibi trafik kurallarının etkisinin halen kendisini göstermesi bu farklılığa açıklama olarak gösterilebilir (Dilmaç ve ark., 1998; Özkan ve ark., 2014; 2015b; 2016).

Söz konusu çalışmanın sözü edilmesi gereken katkıları ile beraber sınırlılıkları da bulunmaktadır. İlk olarak bu çalışma Türkiye'de yapılmış az sayıda emniyet kemeri gözlem çalışmasından biridir. Çalışma özellikle trafik kazaları ve kayıplar açısından riskli bir bölgede yapıldığından, geliştirilebilecek uygulamalar için faydalı bir ön-analiz sunmaktadır. Değinildiği üzere çalışmanın yapıldığı bölgenin nüfusunu büyük oranda üniversite öğrencileri oluşturduğundan, genç nüfusun ağırlıkta olduğu bir bölgedir. Çalışma bir gözlem çalışması olduğundan katılımcıların yaşları kesin olarak bilinememekle beraber, özellikle kampüs girişi ve kampüs içinde yapılan gözlemler göz önüne alındığında, genç sürücülerle ilgili çıkarımlar yapmak mümkün olabilmektedir. Bahsedilmesi gereken önemli bir nokta olarak, çalışmada üniversite çevresi ve genç sürücüler temele alınmak istendiğinden, Şile ilçesi merkezinde gözlem yapılmamış olmasıdır. Araştırmanın bir kısıtlılığ ilçesine genellenemeyeceğinin altı önemle çizilmelidir. İleride yapılacak çalışmalara bu bölge de dahil edilerek daha geniş çapta bilgiye ulaşılabilir. Araştırmanın diğer bir kısıtlılığı ise toplamda 400 araçlık bir gözlemin yapılmış olmasıdır. Bu rakam her ne kadar Eby (2000) tarafından belirlenen minimum gözlem sayısının üzerinde olsa da, daha yüksek düzeyde genellenebilirlik için ileride yapılacak çalışmalarda daha geniş bir örnekleme ulaşılması önerilmektedir. Bununla birlikte, ileride yapılacak çalışmalarda radar sistemleri aracılığı ile hız ile ilgili ölçümlerin de alınması ve bulguların farklı istatistiksel yöntemler kullanılarak analiz

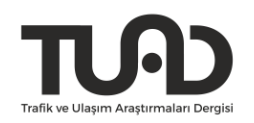


edilmesi önerilebilir. Son olarak, yapılan gözlem sonuçlarında elde edilen bazı bulguların hücre başına beş gözlemden az olması araştırmanın bir kısıtlılığıdır. Bulgular incelendiğinde emniyet kemeri kullanan farklı araç tipleri sürücüleri ile emniyet kemeri kullanan arka koltuk yolcularına ilişkin yapılan gözlem sayılarının düşük olduğu görülmektedir. İstatistiksel açıdan daha güvenilir sonuçlar elde etmek için ileride yapılacak çalışmalarda yapılan gözlem sayısının arttırılması faydalı olacaktır.

Çalışmanın önemli bir katkısı, arka koltuk yolcularına ilişkin gözlem verisi toplanmış olmasıdır. Türkiye'de son yıllarda emniyet kemeri kullanımına ilişkin yapılan en geniş çaptaki çalışmalarda (Özkan ve ark., 2016) arka koltuk yolcularına ilişkin bir veri bulunmamaktadır. Bu sebeple söz konusu çalışmalara oranla çok küçük çapta bir çalışma olmasına karşın, bu çalışmanın önemli bir katkı sağladığı düşünülmektedir. Gözlem çalışmalarında sık karşılaşılan bir kısıtlılık olarak, söz konusu çalışmada gözlem yapılan bölgelerin fiziki koşulları gereği araştırmacılar sürücüler tarafından fark edilmişlerdir. İleride yapılacak çalışmalarda bu durumun önüne geçilmesi adına gözlemcilerin sürücülere kendilerini belli etmeden kayıt ve görüntü almaları önerilebilir. Çalışmadan elde edilen çıktılar temel alınarak, bölgedeki trafik ortamı ile ilgili riskler ve emniyet kemerinin koruyucu rolü bilgilendirmelerin hazırlanması, böylece trafik kurallarına uygun araç kullanımına katkı sağlanması çalışmanın olası çıktılarından biridir. 


\section{Kaynakça}

Akay, D. ve Kurt M. (2006). Otomobil Emniyet Kemeri Kullanılabilirlik Testi. Gazi Üniversitesi Mühendislik-Mimarlık Fakültesi Dergisi, 21(1), 183-191.

Amerikan Ulusal Karayolu Trafik Güvenliği İdaresi (2008). Trafik Güvenliği Durumu. 2008 Yılında Emniyet Kemeri Kullanımı. http://www-nrd.nhtsa.dot.gov/Pubs/811036.PDF.

Ayazsın, U. (20 Ağustos 2017). Şile yolunda kaza: İki çocuk bir kadın yaralı. Hürriyet. 14 Nisan 2018. http://www.hurriyet.com.tr/sile-yolunda-kaza-iki-cocuk-bir-kadin-yarali40555745 .

Boyle, J. M., Lampkin, C. ve Schulman, R. (2008). 2007 motor vehicle occupant safety survey. Volume 2, Seat belt report (No. DOT-HS-810-975). United States. National Highway Traffic Safety Administration, 14-15.

Calisir, F. ve Lehto, M. R. (2002). Young drivers' decision making and safety belt use. Accident Analysis \& Prevention, 34(6), 793-805.

Chaffe, R. H., Leaf, W. A. ve Solomon, M. G. (2006). Seat belt use in Florida. Tallahassee: Florida Department of Transportation, 14-16.

Chaudhary, N. K., Alonge, M. ve Preusser, D. F. (2005). Evaluation of the Reading, PA nighttime safety belt enforcement campaign: September 2004. Journal of Safety Research, 36(4), 321-326.

Chaudhary, N. K., Solomon, M. G. ve Cosgrove, L. A. (2004). The relationship between perceived risk of being ticketed and self-reported seat belt use. Journal of Safety Research, 35(4), 383-390.

Chliaoutakis, J. E., Gnardellis, C., Drakou, I., Darviri, C. ve Sboukis, V. (2000). Modelling the factors related to the seatbelt use by the young drivers of Athens. Accident Analysis \& Prevention, 32(6), 815-825.

Çoban, C. (1 Ağustos 2017). 3 hafriyat kamyonu birbirine girdi: 2 yaralı. Hürriyet. 14 Nisan 2018. http://www.hurriyet.com.tr/gundem/3-hafriyat-kamyonu-birbirine-girdi-2-yarali40537073.

Çukurca, E. (2010). Emniyet kemeri kullanma konusunda yapılan istatistiklerin karşılaştırılması: Ankara örneği, Yayınlanmamış yüksek lisans tezi, Gazi Üniversitesi, 12-51.

DHA. (20 Haziran 2016). Şile'de feci kaza: 1 ölü. En Son Haber. 13 Nisan 2018. http://www.ensonhaber.com/silede-feci-kaza-1-olu-2016-06-20.html.

Diaz, E. M. (2002). Theory of planned behavior and pedestrians' intentions to violate traffic regulations. Transportation Research Part F: Traffic Psychology and Behaviour, 5(3), 169-175.

Dilmaç, B., Çakar, M., Kulaksızoğlu, A. ve Şirin, A. (1998). Sürücülerin kaygı seviyeleri ile seçilmiş bazı sürücü davranışları arasındaki ilişki. Atatürk Eğitim Fakültesi Eğitim Bilimleri Dergisi. 10, 191-210.

Dünya Sağlık Örgütü. (2009a). Karayolu güvenliği konusunda küresel duru raporu: Önlem zamanı. Geneva, İsviçre Dünya Sağlı Örgütü, 2009 (www.who.int/violence_injury_prevention/road_safety_status/2009), 7-8.

\section{TQD}


Dünya Sağl1k Örgütü. (2009b). Seat-belts and child restraints: a road safety manual for decision-makers and practitioners. Londra: FIA Foundation for the Automobile and Society, 159-161.

Dünya Sağlık Örgütü. (2015). Yol güvenliği hakkındaki genel durum raporu. Geneva, İsviçre: DSÖ. 2015.

Eby, D. W. (2000). How often do people use safety belts in your community? A step-by-step guide for assessing community safety belt use.

Eby, D. W. (2011). Naturalistic observational field techniques for traffic psychology research. In Handbook of traffic psychology (pp. 61-72).

Ekici, A. (2014). Trafik Güvenliği Kampanya Modeli ve Uygulaması. Kazaların Çevresel ve Teknik Araştırması Anabilim Dalı, Gazi Üniversitesi Fen Bilimleri Enstitüsü. Yüksek Lisans Tezi. Ankara, 41-136.

European Transport Safety Council. (2015). Promoting seat belt use, https://etsc.eu/newsurvey-reveals-many-europeans-still-dont-take-seatbelt-laws-seriously/

Forjuoh, S. N. (2003). Traffic-related injury prevention for low-income countries. Injury Control and Safety Promotion, 10(1-2), 109-118.

Javadi, S. M. H., Azad, H. F., Tahmasebi, S., Rafiei, H., Rahgozar, M. ve Tajlili, A. (2015). Study of psycho-social factors affecting traffic accidents among young boys in Tehran. Iranian Red Crescent Medical Journal, 17(7).

Jermakian, J. S. ve Weast, R. A. (2017). Passenger use of and attitudes toward rear seat belts. Journal of Safety Research, 64, 113-119.

Jonah, B. A. (1997). Sensation seeking and risky driving: a review and synthesis of the literature. Accident Analysis \& Prevention, 29(5), 651-665.

Keskin, S. (2013). Kırşsehir Trafik Polislerinin Denetim, Hız, Alkollü Sürüş ve Emniyet Kemerine Bakış Açılarının Değerlendirilmesi. T.C Polis Akademisi Güvenlik Bilimleri Enstitüsü Ulaşım Güvenliği ve Yönetimi Anabilim Dalı. Yüksek Lisans Tezi. Ankara, 101-121.

Kırcalı, N. (25 Ağustos 2016). Şile yolunda servis minibüsü devrildi; 1 kişi öldü 4 kişi yaraland1. Hürriyet. http://www.hurriyet.com.tr/sile-yolunda-servis-minibusu-devrildi1-kisi-o-40208092.

Kim, S. ve Kim, K. (2003). Personal, temporal and spatial characteristics of seriously injured crash-involved seat belt non-users in Hawaii. Accident Analysis \& Prevention, 35(1), 121-130.

Nitzburg, M. ve Knoblauch, R. (2004). Rural Pickup Truck Drivers and Safety Belt Use: Focus Group Report (No. HS-809 711).

Özkan, T., Öztürk, İ., Üzümcüoğlu, Y., Bıçaksız, P., ..., Kurban S. (2015a). Trafik Kurul Kararlarının Analizi - Türkiye Değerlendirmesi. Emniyet Genel Müdürlüğü, http://www.trafik.gov.tr/SiteAssets/Yayinlar/Bildiriler/pdf/Trafik\%20Kur... adresinden alınmıştır.

Özkan, T., Üzümcüoğlu, Y,...., Dağaşan, S. (2014). Türkiye Analizi: Takip Çalışması Sürücü ve Ön Koltuk Yolcularının Emniyet Kemeri Kullanımı. Emniyet Genel Müdürlüğü,

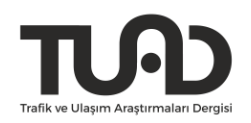


http://www.trafik.gov.tr/SiteAssets/Yayinlar/Kitaplar/Emniyet\%20Kemeri\%20Nihai\% 20Rapor.pdf adresinden alınmıştır, 10-12.

Özkan, T., Üzümcüoğlu, Y., Öztürk, İ., ..., Yaylac1, O. (2015b). Türkiye Analizi: Takip Çalışması Sürücü ve Ön Koltuk Yolcularının Emniyet Kemeri Kullanımı. Emniyet Genel Müdürlüğü, http://www.trafik.gov.tr/SiteAssets/Yayinlar/Kitaplar/Emniyet_Kemeri_2015.pdf adresinden alınmıştır, 10-18.

Özkan, T., Üzümcüoğlu, Y., Kaçan, B., Arslan, B., Tekeş, B., Öz, C., Azık, D., Solmazer, G., Fındık, G., Öztürk, İ., Ersan, Ö., Bıçaksız, P., Yılmaz, Ş. ve Erkuş, U.U. (2016). Türkiye Analizi: Takip Çalışması Sürücü ve Ön Koltuk Yolcularının Emniyet Kemeri Kullanımı. Emniyet Genel Müdürlüğü, http://www.trafik.gov.tr/SiteAssets/Yayinlar/Kitaplar/Emniyet_Kemeri_2016.pdf adresinden alınmıştır, 11-23.

Reason, J., Manstead, A., Stradling, S., Baxter, J. ve Campbell, K. (1990). Errors and violations on the roads: a real distinction?. Ergonomics, 33(10-11), 1315-1332.

Shaaban, K. (2018). Self-Report and Observational Assessment and Investigation of Seat Belt Use Among Young Drivers and Passengers: The Case of Qatar. Arabian Journal for Science and Engineering, 1-11.

Strine, T. W., Beck, L. F., Bolen, J., Okoro, C., Dhingra, S. ve Balluz, L. (2010). Geographic and sociodemographic variation in self-reported seat belt use in the United States. Accident Analysis \& Prevention, 42(4), 1066-1071.

Sümer, N. (2002). Trafik Kazalarında Sosyal Psikolojik Etmenler: Sürücü Davranışları, Becerileri ve Sosyal Politik Çevre. Türk Psikologlar Derneği, 5(9-10)1-36.

Şile’de feci kaza! Kaza yapan üniversite ögrencileri yola savruldu: 1 ölü 2 yaralı. (28 Şubat 2013). Sözcü. 13 Nisan 2018, https://www.sozcu.com.tr/2013/gunun-icinden/siledefeci-kaza-238109/.

Şile'de kaza: Üniversite ögrencisi öldü. (8 May1s 2010). Haber7com. 14 Nisan 2018, http://www.haber7.com/3sayfa/haber/527131-silede-kaza-universite-ogrencisi-oldu.

Şimşekoğlu, Ö. (2005). Correlates of seat belt use among turkush front seat occupants. Yayınlanmamış Yükseklisans Tezi, Orta Doğu Teknik Üniversitesi, Sosyal Bilimler Enstitüsü, 6-18.

Şimşekoğlu, Ö. (2009). Factors related to seat belt use: A Turkish case. Yayınlanmamış Doktora Tezi, Psikoloji Bölümü, Helsinki Üniversitesi, 9-15.

Şimşekoğlu, Ö. ve Lajunen, T. (2008). Social psychology of seat belt use: A comparison of theory of planned behavior and health belief model. Transportation Research Part F: Traffic Psychology and Behaviour, 11(3), 181-191.

Taylor, S. E., Peplau, L. A. ve Sears, D. O. (2010). Sosyal psikoloji. İmge Kitabevi.

T.C Başbakanlık Mevzuatı Geliştirme ve Yayın Genel Müdürlüğü. (1997). Karayolları Trafik Yönetmenliği (Yayın no: 23053). Ankara: Mevzuat bilgi sistemi. http://www.mevzuat.gov.tr/Metin.Aspx?MevzuatKod=7.5.8182\&MevzuatIliski=0\&so urceXmlSearch=karayollar\%C4\%B1\%20trafik.

\section{TQD}


T.C Emniyet Genel Müdürlüğü Trafik Hizmetleri Başkanlığı. (1999). Ülkemizde Emniyet Kemeri Kullanımı. Trafik Araştırma Merkezi Müdürlüğü Yayınları, Ankara.

T.C Emniyet Genel Müdürlüğü Trafik Araştırma Merkezi Müdürlügü̈. (2009). Emniyet kemeri ve çocuk koruma sistemleri: karar organları ve uygulayıcıları için el kitabı. EGM Yayın katalog numaras1:546.

Tekyol, D. (2017). Araç içi trafik kazalarına bağll yaralanmalarda emniyet kemeri ve hava yastı̆̆ının travma şiddet skoru ile ilişkisinin incelenmesi. Yüksek lisans tezi, T.C Sağlık Bakanlığı Haydarpaşa Numune Eğitim ve Araştırma Hastanesi Acil Tıp Kliniği, 8-16.

Uluslararası Trafik Güvenliği ve Veri Analiz Grubu. (2018). Yıllık Yol Güvenliği Raporu. https://www.itf-oecd.org/sites/default/files/docs/irtad-road-safety-annual-report2018_0.pdf , 52-56.

Vivoda, J. M. ve Eby, D. W. (2011). Factors influencing safety belt use. In Handbook of traffic psychology (pp. 215-229).

Vivoda, J. M., Eby, D. W. ve Kostyniuk, L. P. (2004). Differences in safety belt use by race. Accident Analysis \& Prevention, 3(6), 1105-1109.

Wilde, G. J. (1998). Risk homeostasis theory: an overview. Injury Prevention, 4(2), 89-91. 